\title{
The health benefits of smoking cessation for adult smokers and for pregnant women in Taiwan
}

\author{
C P Wen, T Y Cheng, C-L Lin, H-N Wu, D T Levy, L-K Chen, C-C Hsu, M P Eriksen, H-J Yang, S P Tsai
}

Tobacco Control 2005;14(Suppl I):i56-i61. doi: 10.1136/tc.2004.007997

See end of article for authors' affiliations

\section{Correspondence to:} Chi Pang Wen, National Health Research Institutes, 35 Keyan Road, Zhunan Town, Miaoli County, Taiwan 350; Cwengood@ nhri.org.tw

\begin{abstract}
Objective: To assess the benefits of smoking cessation regarding mortality reduction after smokers quit, and regarding the health of newborns after smoking mothers quit.

Methods: Relative mortality risks (RR) for smokers aged 35 or older who quit years ago were calculated from the follow up of 71361 civil servants and teachers recruited since 1989. Data from the Pregnancy Risk Assessment Monitoring System in Taipei City were used to calculate the odds ratios of body weights of newborns born to mothers of different smoking status.

Results: Mortality risk for ex-smokers was significantly lower than that of current smokers for all causes (18\%), all cancer (22\%), lung cancer (39\%), and ischaemic heart disease (54\%). These benefits were not distinguishable initially, up to five years, but by year 17 and thereafter, substantial benefits of cessation accrued. Two thirds of smoking women quit during the first trimester of pregnancy, and only $2.2 \%$ of mothers smoked throughout pregnancy. The newborns from smoking mothers were smaller than those from never smoking mothers, but, if these mothers quit early in the first trimester, birth weights were normal.

Conclusions: The health benefits of smoking cessation, rarely reported for Asian populations, have been largely ignored by smokers in Taiwan, where cessation activities have been extremely limited. Findings of this study that risks from smoking can be attenuated or reversed should be widely communicated to motivate smokers to quit. Smokers should quit early, including smoking mothers, and not wait till medical conditions surfaced, to have the maximal benefits of cessation.
\end{abstract}

$\mathrm{T}$ hrough anti-smoking efforts by the Taiwan government, public awareness of the health hazards of smoking has substantially increased. ${ }^{1}$ The increased awareness was intended to prevent new smokers from commencing and to reduce the number of smokers. However, the number of smokers in Taiwan has remained stable in the last decade when anti-smoking campaigns increased. ${ }^{2}$ The campaigns emphasised the hazards of smoking. but caused few smokers to quit, with many smokers simply switching to light cigarettes. ${ }^{3}$ As eight out of 10 smokers in Taiwan surveyed agreed with the statement that smoking causes lung cancer, the lack of significant progress in cessation reflects not so much of a lack of appreciation of the seriousness of health hazards, but reflects more a lack of easy access to or effective incentives for cessation services, providing encouraging information on the benefits of cessation.

There are far more smokers than ex-smokers in Taiwan, with the smoker/ex-smoker ratio being seven times higher than that in the USA. ${ }^{6}$ The extensive literature on the health benefits of cessation has been summarised by the US Surgeon General, ${ }^{7}$ and the financial and clinical effectiveness of addiction based "cessation treatment" have been established..$^{8-11}$ The benefits of quitting by smoking mothers have also been well documented. ${ }^{12-19}$ Few of these benefits of cessation, however, have been developed from studying Asian populations. ${ }^{20}$ Critics claim that, not only may there be genetic differences, but also differences in smoking behaviour, such as in the type of cigarettes smoked, in the quantity smoked, or the length of time smoked. ${ }^{21}$ As a result, smokers in Taiwan argued that the results may not be fully applicable to them, and these differences may affect the magnitude of hazards and the extent of benefits. ${ }^{2}$ For example, eight out of 10 Taiwanese smokers chose to smoke the leading domestic brand "Long Life", with many of them believing that the adverse health effect of this brand could be different from other brands. This example illustrates the need for Taiwan specific information on smoking harm and cessation benefits.

The purpose of this paper is to quantify the benefits of smoking cessation in terms of mortality reduction after cessation, and for the health of newborns after smoking mothers quit. Two sets of Taiwanese data were used to identify the benefits of cessation. The mortality experience of smokers who had quit for various lengths of time were compared to that for continuing smokers, and the birth weights of newborns from mothers who quit early in pregnancy were compared those of mothers who continued to smoke.

\section{METHODS \\ Relative mortality risks for ex-smokers}

The study cohort consisted of 71361 government employees and teachers who underwent annual medical screenings between 1989 and 1992 at the Taipei Outpatient Service Center. ${ }^{21}$ These medical screenings were offered by their employers as a part of their benefit programmes.

Current smokers were those smoking at the time of recruitment, while ex-smokers were those who had quit for at least six months. For smokers, additional information on the age of initiation, duration and quantity smoked, and for ex-smokers, number of years quit, were collected. Vital status as of 31 December 2001 and causes of death information were ascertained through matches between the personal identification number of cohort members and computerised

Abbreviations: $\mathrm{Cl}$, confidence interval; CPS, cancer prevention study; ETS, environmental tobacco smoke; ICD-9, International classification of diseases $9^{\text {th }}$ revision; LBW, low birth weight; OR, odds ratio; NRT, nicotine replacement therapy; PRAMS, Pregnancy Risk Assessment Monitoring System; RR, relative risk; SES, socioeconomic status 
national death files. The causes of death were classified by the International classification of diseases $9^{\text {th }}$ revision (ICD-9). Only those males aged 35 or older were included in the calculation of smokers' and ex-smokers' mortality experience.

The age adjusted relative risks of mortality for ex-smokers were compared to those of current smokers and non-smokers using Cox's proportional hazards model (SAS PHREG Procedure). ${ }^{22}$ Relative risks (RR) and 95\% confidence intervals (CI) were calculated for each cause of death.

\section{Birth weight of infants of never smoking, quitting, and} continuing smoking mothers

Data on birth outcomes and smoking status of pregnant women came from the Pregnancy Risk Assessment Monitoring System (PRAMS) in Taipei City. With the use of a standard registration form, the nurses at the prenatal clinics entered maternal information such as smoking status and later reported pregnancy outcomes into the system after delivery. A total of 11131 births were reported in an 18 month period, between January 2002 and June 2003. All seven municipal hospitals in Taipei City participated in the PRAMS system.

Through interviews by clinic nurses, the smoking status of each pregnant woman was identified. Quitting mothers were those who indicated quitting before or by the time of the first prenatal visit in the first trimester. Smoking/non-quitting mothers were those who continued to smoke beyond the first trimester. Twins and still births were excluded. Of the 11131 total births, there was information on birth weight of 9499 single, live births, or a completion rate of $85 \%$. Newborns weighing less than $2500 \mathrm{~g}$ were classified as low birth weight (LBW). ${ }^{12}$ The frequency of mothers by smoking status, age, education, parity (whether the first or later child), and sex of child was tabulated. The odds ratios (OR) of a LBW baby and its $95 \%$ CI were calculated using logistic regression methods ${ }^{22}$ distinguishing between smoking, quitting, and never smoking mothers. We controlled for age of the mother, sex of the child, parity, and existence of alcohol habit.

\section{RESULTS}

\section{Relative mortality risks and benefits of cessation of adult male ex-smokers}

The studied cohort included 30244 male subjects, aged 35 years or older, and were followed up for an average of 11 years. In contrast to the national prevalence of adult male smokers at $46.8 \%$ and ex-smokers at $6.8 \%,{ }^{5}$ there were $29.4 \%$ smokers and $13.6 \%$ ex-smokers in this cohort, reflecting the lower rate of smoking and higher rate of cessation in this better educated and higher socioeconomic class of the cohort.

Table 1 lists the age adjusted relative risks of smoker and ex-smoker groups with the never smoker group as the comparison. Both smokers and ex-smokers had increased relative risks for deaths from all causes (RR 1.60 and 1.33, respectively) and from all cancer (RR 1.80 and 1.47, respectively). In addition, smokers had significantly higher risks for death from lung cancer, cardiovascular diseases, ischaemic heart disease, and all accidents. For ex-smokers, the relative risks showed similar increases in several causes, but with significance found only for lung cancer.

Table 2 provides a direct comparison between ex-smokers and smokers. Ex-smokers showed significantly reduced mortality risks for all causes (18\%) and for all cancer $(22 \%)$ when compared to smokers. Lung cancer was reduced by $39 \%$, and ischaemic heart disease by half (54\%). Risk for all accidents was also lower.

The benefits derived from different lengths of cessation are shown in table 3. Due to the small number of deaths in exsmokers, not all relative risks were significant, although a beneficial trend was found with time since quitting. Those who quit for five years or less had non-significant reductions in risk relative to current smokers for all causes (RR 0.95). Those who had quit for more than 16 years had substantially reduced risks for deaths from all causes $(28 \%)$, all cancer $(40 \%)$, lung cancer (68\%) for all ages, and ischaemic heart disease $(46 \%)$ for those in the middle adult age.

\section{Birth weight of infants of never smoking, quitting, and continuing smoking mothers}

As shown in table 4, there were 9499 mothers having their live births registered in Taipei City, with $6.4 \%$ indicating that they smoked before this pregnancy. At the prenatal clinic visits during the first trimester, two thirds of smoking mothers $(4.2 \%$ of all mothers) indicated they already quit smoking. The remaining one third or $2.2 \%$ continued to smoke beyond the first trimester. The majority (54\%) of pregnancies of smoking (non-quitting) mothers were for second child or subsequent births, while two thirds of quitters were for primigravida $(64 \%, \mathrm{p}<0.05)$. Never smoking mothers were more educated, and tended to be older, with more than half of their pregnancies being their first.

Table 1 Age adjusted relative risks (RR) and 95\% confidence intervals (CI) for smokers and for ex-smokers when compared to non-smokers

\begin{tabular}{|c|c|c|c|c|c|}
\hline \multirow[b]{2}{*}{ Causes of death } & \multirow[b]{2}{*}{ ICD-9 code } & \multicolumn{2}{|c|}{ Smokers } & \multicolumn{2}{|c|}{ Ex-smokers } \\
\hline & & RR & $95 \% \mathrm{Cl}$ & RR & $95 \% \mathrm{Cl}$ \\
\hline All cause & $001-998$ & $1.60^{*}$ & 1.48 to 1.83 & $1.33^{*}$ & 1.13 to 1.55 \\
\hline All cancer & $140-208$ & $1.80^{*}$ & 1.48 to 2.19 & $1.47^{*}$ & 1.16 to 1.87 \\
\hline Stomach cancer & 151 & 1.57 & 0.88 to 2.81 & 1.70 & 0.89 to 3.25 \\
\hline Liver cancer & $155-156$ & 1.34 & 0.90 to 1.99 & 1.08 & 0.66 to 1.77 \\
\hline Lung cancer & 162 & $4.25^{\star}$ & 2.68 to 6.74 & $3.34^{*}$ & 1.91 to 5.84 \\
\hline Diabetes mellitus & 250 & 1.26 & 0.66 to 2.42 & 1.48 & 0.77 to 2.83 \\
\hline Cardiovascular diseases & $390-459$ & $1.57^{*}$ & 1.20 to 2.08 & 1.24 & 0.90 to 1.72 \\
\hline Ischaemic heart disease & $410-414$ & $2.25^{\star}$ & 1.44 to 3.53 & 1.00 & 0.54 to 1.84 \\
\hline Person aged 35-64 & & $2.49^{*}$ & 1.52 to 4.10 & 1.15 & 0.56 to 2.36 \\
\hline Person aged 65+ & & 1.41 & 0.44 to 4.53 & 0.67 & 0.20 to 2.23 \\
\hline Cerebrovascular disease & $430-438$ & 1.41 & 0.89 to 2.26 & 1.53 & 0.92 to 2.52 \\
\hline Person aged $35-64$ & & 1.40 & 0.85 to 2.29 & 1.63 & 0.96 to 2.80 \\
\hline Person aged 65+ & & 1.47 & 0.33 to 6.61 & 0.81 & 0.19 to 3.38 \\
\hline Respiratory diseases & $460-519$ & 1.38 & 0.67 to 2.85 & 1.19 & 0.58 to 2.43 \\
\hline All accidents & $800-949$ & $1.81^{*}$ & 1.11 to 2.96 & 1.22 & 0.62 to 2.40 \\
\hline Motor vehicle accidents & $810-829$ & 1.97 & 0.94 to 4.13 & 0.82 & 0.26 to 2.52 \\
\hline Non-motor vehicle accidents & $850-929$ & 1.66 & 0.83 to 3.33 & 1.50 & 0.61 to 3.72 \\
\hline
\end{tabular}


Table 2 Age adjusted relative risks (RR) and 95\% confidence intervals (CI) for ex-smokers compared to current smokers

\begin{tabular}{llrll}
\hline Causes of death & ICD-9 code & $\begin{array}{c}\text { No. of } \\
\text { deaths }\end{array}$ & RR & 95\% Cl \\
\hline All cause & $001-998$ & 670 & 0.82 & 0.70 to $0.97^{*}$ \\
All cancer & $140-208$ & 306 & 0.78 & 0.61 to $0.99^{*}$ \\
$\quad$ Stomach cancer & 151 & 37 & 0.96 & 0.49 to 1.88 \\
$\quad$ Liver cancer & $155-156$ & 65 & 0.87 & 0.52 to 1.46 \\
$\quad$ Lung cancer & 162 & 86 & 0.61 & 0.38 to $0.98^{*}$ \\
Diabetes mellitus & 250 & 31 & 0.81 & 0.39 to 1.68 \\
Cardiovascular diseases & $390-459$ & 153 & 0.81 & 0.58 to 1.14 \\
$\quad$ Ischaemic heart disease & $410-414$ & 57 & 0.46 & 0.25 to $0.84^{*}$ \\
$\quad$ Person aged 35-64 & & 48 & 0.45 & 0.23 to $0.89^{*}$ \\
$\quad$ Person aged 65+ & & 9 & 0.55 & 0.14 to 2.13 \\
Cerebrovascular disease & $430-438$ & 57 & 0.91 & 0.53 to 1.56 \\
$\quad$ Person aged 35-64 & & 51 & 1.22 & 0.70 to 2.14 \\
$\quad$ Person aged 65+ & & 6 & 0.42 & 0.08 to 2.20 \\
Respiratory diseases & $460-519$ & 27 & 1.19 & 0.54 to 2.62 \\
All accidents & $800-949$ & 43 & 0.66 & 0.34 to 1.31 \\
$\quad$ Motor vehicle accidents & $810-829$ & 18 & 0.49 & 0.16 to 1.51 \\
$\quad$ Non-motor vehicle accidents & $850-929$ & 22 & 0.78 & 0.31 to 1.96 \\
\hline * $<$ <0.05. & & & & \\
\hline
\end{tabular}

The birth weights of newborns from mothers who smoked throughout pregnancy were significantly smaller than babies of never smoking mothers, with an average of $157 \mathrm{~g}$ less birth weight per infant (table 5). They were also significantly smaller than babies from smoking mothers who quit in the first trimester, with an average of $168 \mathrm{~g}$ less birth weight per infant. There was no difference between the birth weight of infants of never smoking and quitting mothers $(p=0.63)$. The proportion of mothers having LBW infants, defined as less than $2500 \mathrm{~g}$ birth weight, was significantly higher (OR 1.7) for smoking mothers when compared with never smoking mothers, with age, education, parity, and alcohol drinking adjusted. Quitters did not differ from never smokers in their propensity to have LBW infants.

\section{DISCUSSION}

This study provides strong evidence for two types of benefits from smoking cessation in this population: (1) after smokers quit, mortality risk from smoking related diseases decreased, with the amount of reduction increasing over time; and (2) the birth weight of the newborns significantly improved as smoking mothers quit smoking at or before first trimester. These favourable results from smokers after quitting, extensively studied in the Western populations, have rarely been reported in Asian populations. ${ }^{7}$

After smokers quit, ex-smokers experienced mortality benefits for all causes. Ex-smokers also reduced the risks of dying from all cancers, lung cancer, respiratory disease, and accidental deaths. Similar beneficial results have been seen in different cohorts, such as British doctors, ${ }^{23}$ the Danish population, ${ }^{24}$ and, most impressively, the one million volunteers in the American Cancer Society study of CPS-II (cancer prevention study). ${ }^{7}$ In the CPS-II study, ex-smokers' risks decreased gradually with time since cessation for 15 or more years, until their risks approached those of nonsmokers. In our study, it also took 17 years or longer for ex-smokers to reduce their overall risks significantly. Different mortality risks among ex-smokers decreased at different paces. For example, heart disease risks decreased most in the first five years. Cancer risks fell after smokers quit for more than 10-15 years, if at all. ${ }^{25}$ Accidental injury risks observed in this study are likely to benefit ex-smokers shortly after they quit.

When the proportion of ex-smokers at each age group was compared, the quit rate increased linearly with increasing age. ${ }^{26}$ As demonstrated in nationwide surveys in Taiwan, more than $80 \%$ of ex-smokers attribute their cessation to health concerns as they become older. ${ }^{12}$ Many of these smokers quit only after serious medical conditions develop and would show limited benefits from cessation, or even temporarily increased risks, compared to ex-smokers without medical conditions. The mortality experience of ex-smokers immediately after quitting had improved slightly in this study, but was not significantly different from that of continuing smokers. This paradoxical phenomenon was also observed in the American Cancer Society's CPS-II study, where overall mortality ratios of ex-smokers were higher than smokers in the first two years after cessation. The most likely explanation for this is that many smokers who quit for medical reasons do so too late to experience the benefits of cessation.

That only a small fraction of smokers had quit in Taiwan was highlighted by the sevenfold difference between the number of smokers and ex-smokers. A reduction of this ratio

Table 3 Relative risks (RR) by number of years from quitting among male ex-smokers compared with smokers

\begin{tabular}{|c|c|c|c|}
\hline & $0-5$ years & $0-16$ years & 17 years+ \\
\hline Causes of death & $\operatorname{RR}(95 \% \mathrm{Cl})$ & $\operatorname{RR}(95 \% \mathrm{Cl})$ & $\operatorname{RR}(95 \% \mathrm{Cl})$ \\
\hline $\begin{array}{l}\text { All causes combined } \\
\text { All cancer combined } \\
\text { Lung cancer } \\
\text { Ischaemic heart disease } \\
\text { (aged 35-64) }\end{array}$ & $\begin{array}{l}0.95(0.76 \text { to } 1.19) \\
0.74(0.51 \text { to } 1.06) \\
0.42(0.18 \text { to } 0.98)^{*} \\
0.62(0.24 \text { to } 1.58)\end{array}$ & $\begin{array}{l}0.85(0.71 \text { to } 1.02) \\
0.80(0.61 \text { to } 1.05) \\
0.66(0.39 \text { to } 1.11) \\
0.43(0.19 \text { to } 0.96)^{*}\end{array}$ & $\begin{array}{l}0.72(0.54 \text { to } 0.96)^{*} \\
0.60(0.38 \text { to } 0.94)^{*} \\
0.32(0.11 \text { to } 0.91)^{*} \\
0.54(0.17 \text { to } 0.78)^{*}\end{array}$ \\
\hline
\end{tabular}


Table 4 Demographic description of pregnant women and newborns

\begin{tabular}{|c|c|c|c|c|}
\hline Variables & $\begin{array}{l}\text { Never smoking } \\
\text { mothers } \\
\text { n (\%) }\end{array}$ & $\begin{array}{l}\text { Quitting } \\
\text { mothers } \\
\text { n (\%) }\end{array}$ & $\begin{array}{l}\text { Non-quitting } \\
\text { mothers } \\
\text { n (\%) }\end{array}$ & Total \\
\hline Total & $8892(93.6)$ & $400(4.2)$ & 207 (2.2) & 9499 (100\%) \\
\hline \multicolumn{5}{|l|}{ Age of pregnant mothers } \\
\hline$<24$ years & 1299 (14.6) & $134(33.5)$ & $85(41.1)$ & $1518(16.0 \%)$ \\
\hline $25-29$ years & 3248 (36.5) & $143(35.7)$ & $60(29.0)$ & $3451(36.3 \%)$ \\
\hline$>30$ years & $4345(48.9)$ & $123(30.8)$ & $62(30.9)$ & $4530(47.7 \%)$ \\
\hline \multicolumn{5}{|l|}{ Parity* } \\
\hline First (primigravida) & $4692(55.8)$ & $256(64.0)$ & $96(46.4)$ & $5044(53.1 \%)$ \\
\hline Second or more & 4198 (47.2) & $144(36.0)$ & $111(53.6)$ & $4452(46.9 \%)$ \\
\hline \multicolumn{5}{|l|}{ Education level of mothers* } \\
\hline Middle school or below & $859(9.7)$ & $46(11.5)$ & $57(27.5)$ & $962(10.3 \%)$ \\
\hline High school & $2938(33.0)$ & $270(67.5)$ & $131(63.3)$ & $3339(35.7 \%)$ \\
\hline College or above & $4964(55.8)$ & $79(19.7)$ & $18(8.7)$ & $5061(54.0 \%)$ \\
\hline \multicolumn{5}{|l|}{ Sex of newborn } \\
\hline Male & $4685(52.7)$ & $221(55.2)$ & $99(47.8)$ & $4805(51.7 \%)$ \\
\hline Female & 4205 (47.3) & $178(44.5)$ & $107(51.7)$ & $4490(48.3 \%)$ \\
\hline
\end{tabular}

to one, requiring nearly half of the smokers in Taiwan to quit successfully, would approximate the tobacco control efforts achieved today in the USA. ${ }^{6}$ Such a low cessation rate is indicative of ineffective cessation efforts and is characteristic of many Asian countries, ${ }^{27}$ and has important implications for the future direction of tobacco control.

The common failure of physicians to advise smokers to quit is believed to play a pivotal role in producing few ex-smokers in Taiwan. ${ }^{28}$ Many physicians in Asian countries have been trained in the USA and have achieved high proficiency in the skills of delivering acute care inside the hospitals, but, in areas such as counselling lifestyle changes at the clinic settings, including smoking cessation, they are poorly prepared. In contrast to their counterparts in the USA, ${ }^{29} 30$ medical societies in Taiwan have never taken a public position on the issue of smoking or the importance of cessation. Furthermore, they are expected to provide cessation services in a medical system that has yet to value highly such services. For example, pharmacotherapy for cessation, such as the use of nicotine replacement therapy (NRT), a proven effective method for cessation, ${ }^{11}{ }^{31}$ is not reimbursable under the National Health Insurance system in Taiwan. Based on industry sales figures, ${ }^{32}$ NRT has been very infrequently used in Taiwan. In any given year in the last decade, less than one in a thousand smokers purchased NRT medication. The high cost of NRT, relative to cigarette price, and the lack of support for motivated physicians contributed to such phenomenon. ${ }^{28}$

The health benefits of cessation were derived from male data only, as there were too few females in the sample to obtain meaningful estimates. While these results are applicable to male smokers only, males constitute more than $90 \%$ of smoking adults in Taiwan. Similarly, while our data were derived from a cohort consisting of individuals of relatively higher education and above average socioeconomic status (SES), the nature of the way relative risks were developed stemmed from an internal comparison to subjects with comparable SES. Thus, these reduced risks and the accrued benefits of cessation observed in this study should be a reasonable estimate for all the smokers in Taiwan.

Our study on smoking during pregnancy in Taiwan confirmed both the increased risk to newborns by smoking mothers and the near reversal of that risk when they quit early. ${ }^{12}$ If smoking mothers quit during or before the first trimester, the weight lowering effect on the newborns could nearly be reversed. This information should serve as an important message to encourage quitting by smoking mothers in order to improve the health of their babies.

The low birth weight observed in this study is a major risk factor for mortality as well as for morbidity of the infants. ${ }^{12}$ LBW infants have an unusually large number of inpatient days in Taiwan. ${ }^{33}$ Depending on their weight, these infants stay in hospital between 23 and 119 days, spending a similar number of days between the intensive care unit (ICU) and the regular ward. The cost of each hospitalisation ranged between US\$5200 and US\$40 000, being 5-40 times the cost of normal delivery. This is but one of the many medical services required for sustaining the life of premature babies. ${ }^{12}$ Publicity for these serious medical complications and financial consequences could help persuade smoking mothers to quit. ${ }^{12} 1519$ Additional benefits of cessation to young child could also be publicised, including reduction of second hand smoke, and reduced risk of sudden infant death syndrome, respiratory illnesses, and infections. ${ }^{12} 3435$

Two thirds of smoking mothers in the sample indicated quitting at or before the first trimester. If such a sharp curtailment of smoking during pregnancy were sustained after delivery, smoking rates would have dropped sharply

Table 5 Comparison of birth weight of infants and proportion of low birth weight (LBW)* by smoking status of pregnant women $(n=9499)$

\begin{tabular}{|c|c|c|c|c|c|c|c|c|}
\hline \multirow[b]{2}{*}{ Smoking status } & \multirow[b]{2}{*}{ Number (\%) } & \multirow{2}{*}{$\begin{array}{l}\text { Mean (SD) birth } \\
\text { weight }(g)\end{array}$} & \multicolumn{2}{|c|}{ LBW infants } & \multirow[b]{2}{*}{ ORf } & \multirow[b]{2}{*}{$(95 \% \mathrm{Cl})$} & \multirow[b]{2}{*}{ OR§ } & \multirow[b]{2}{*}{$95 \% \mathrm{Cl}$} \\
\hline & & & Number & Rate (\%) & & & & \\
\hline Never smoking mothers & $8892(93.6 \%)$ & $3184(430)$ & 430 & 4.8 & 1.0 & & 1.0 & \\
\hline Quitting mothers & $400(4.2 \%)$ & 3195 (447) & 23 & 5.8 & 1.1 & (0.9 to 1.4$)$ & 1.1 & (0.9 to 1.4$)$ \\
\hline Non-quitting mothers & $207(2.2 \%)$ & $3027(450) \dagger$ & 17 & 8.2 & 1.8 & $(1.1$ to 2.9$)$ & 1.7 & $(1.0$ to 2.8$)$ \\
\hline
\end{tabular}

*LBW defined as birth weight less than $2500 \mathrm{~g}$.

†Mean birth weight is statistically smaller than that of never smoking mothers and that of quitting mothers, $\mathrm{p}<0.05$.

fOdds ratios (OR) of quitting mothers or non-quitting mothers in having LBW infants, when compared with proportion of LBW infants by non-smokers

$\S$ Adjusted for mothers' age, educational level of mothers, sex of infants, parity, and alcohol drinking habit. 


\section{What this paper adds}

The benefits of smoking cessation have been less studied in Asian countries than in Western nations. Such knowledge is needed to encourage smokers to quit, and to increase the extremely low cessation rate in Taiwan. In this study smokers reduced mortality risks and babies reversed low birth weight status, as a result of smoking cessation. Publicising that smoking hazards could be attenuated or reversed could motivate smokers to quit.

during the reproductive ages for women. However, a nationally representative survey of 3208 women with small child before the age 5 in Taiwan, indicated that 33 of the 140 smoking women recalled that they had quit during pregnancy, but 29 or $88 \%$ relapsed after delivery. ${ }^{36}$ The extent of relapse can also be indirectly deduced from smoking prevalence during childbearing age groups in Taiwan, increasing from 3.8\% (ages 18-19) and 4.5\% (ages 20-29) to $5.7 \%$ (ages 30-39), with most women (more than 95\%) having had at least one pregnancy by age $40 .{ }^{37}$ That most quitting mothers relapsed after delivery is regrettable, but the beneficial effect of quitting in the first trimester is nevertheless valuable.

The need for support or encouragement for quitting mothers, with more smokers in the lower SES, suggests opportunities for intervention, but presents challenges for effective communication. ${ }^{31}$ The hazards of smoking and the benefits of cessation in reversing the damage done by a smoking mother should be presented in an understandable and convincing format to all levels of educational background. At the same time, low cost services for quitting assistance should be provided. ${ }^{11} 313839$

The pregnancy related benefits of cessation observed in this study may have been underestimated by including those who quit with serious medical conditions, particularly when the results were applied to those smokers who quit without having a medical condition. The risk of LBW by smoking mothers, and the benefits of quitting, may have also been underestimated if they quit smoking as soon as becoming aware of their pregnancy but identified themselves as nonsmokers. Similarly, underestimation occurred, if they continued to smoke but significantly reduced the amount they smoked. Indeed, smoking mothers reduced consumption from a mean (SD) of $12.2(8.2)$ cigarettes per day to 6.7 (15.1) cigarettes per day in this study. The LBWs may have been more pronounced if they maintained their prepregnancy smoking amount. Another possibility for underestimation is that more than half of women of reproductive ages in Taiwan (58\%) were exposed to environmental tobacco smoke (ETS) at home. ${ }^{5}$ These non-smoking women, having high ETS exposures, had been reported to have a higher tendency for having infants of LBW. ${ }^{12}{ }^{40-42}$

\section{Authors' affiliations}

C P Wen, T Y Cheng, L-K Chen, C-C Hsu, Division of Health Policy Research, National Health Research Institutes, Taipei, Taiwan

C-L Lin, H-N Wu, Department of Maternal and Child Medicine, Women and Children Hospital, Taipei, Taiwan

D T Levy, Pacific Institute for Research and Evaluation, Baltimore, Maryland, USA

M P Eriksen, Institute of Public Health, Georgia State University, Atlanta, Georgia, USA

H-J Yang, Ming Sheng General Hospital, Taoyuan, Taiwan

S P Tsai, The University of Texas Health Science Center at Houston,

School of Public Health, Houston, Texas, USA

Competing interests: none declared

\section{REFERENCES}

1 Bureau of Health Promotion. Report of knowledge, attitude and practice $(K A P)$ in health promotion in Taiwan. Taichung, Taiwan: Bureau of Health Promotion, Department of Health, 2003.

2 Taiwan Tobacco and Wine Monopoly Bureau. Report from tobacco and alcohol consumption survey in Taiwan area. Taipei, Taiwan: Taiwan Tobacco and Wine Monopoly Bureau (TTWMB), 1963-1996.

3 Wen CP, Chen T, Tsai YY, et al. Are marketing campaigns in Taiwan by foreign tobacco companies targeting young smokers? Tobacco Control 2005; 14(suppl I):i38-44.

4 Hsieh CR, Hu TW, Lin CJ. The demand for cigarettes in Taiwan: domestic versus imported cigarettes. Contemp Econ Policy 1999;17:223-34.

5 Wen CP, Levy DT, Cheng TY, et al. Smoking behaviour in Taiwan, 2001. Tobacco Control 2005; 14(suppl I):i51-5.

6 Schoenborn CA, Vickerie JL, Barnes PM. Cigarette smoking behavior of adults: United States, 1997-98. In: Advance data from vital and health statistics, No 331. Hyattsville, Maryland: National Center for Health Statistics, 2003.

7 US Department of Health and Human Services. The health benefits of smoking cessation. A report of the Surgeon General, 1990. Rockville, Maryland: Public Health Service, Centers for Disease Control, Office on Smoking and Health, 1990 (DHHS Publication No (CDC) 90-8416.).

8 Curry SJ, Grothaus LC, McAfee T, et al. Use and cost effectiveness of smoking cessation services under four insurance plans in a health maintenance organization. N Engl J Med 1998;339:673-9.

9 Cromwell J, Bartosch WJ, Fiore MC, et al. Cost-effectiveness of the clinical practice recommendations in the AHCPR guideline for smoking cessation. JAMA 1997;278:1759-66.

10 Ahluwalia J. The cost-effectiveness of the nicotine transdermal patch for smoking cessation. Prev Med 1997;26:264-70.

11 Fiore MC, Bailey WC, Cohen CJ. Treating tobacco use and dependence. In U.S Department of Health and Human Services PHS, ed. Clinical Practice Guideline. Rockville, 2000.

12 US Department of Health and Human Services. Women and smoking. A report of the Surgeon General. Washington, DC: US Dept of Health and Human Services, Public Health Service, Office of the Surgeon General, 2001. (DHHS Publication No. (CDC) 90-8416.)

13 British Medical Association. Smoking and reproductive life: the impact of smoking on sexual, reproductive and child health. London: BMA, Board of Science and Education \& Tobacco Control Resource Centre, 2004.

14 Lu MC, Tache V, Alexander GR, ef al. Preventing low birth weight: is prenatal care the answer? J Matern Fetal Neonatal Med 2003; 13:362-80.

15 Messecar DC. Smoking cessation interventions for pregnant women to prevent low birth weight: what does the evidence show? J Am Acad Nurse Pract 2001; 13:171-7.

16 Hueston WJ, Mainous AG, Farrell JB. A cost-benefit analysis of smoking cessation programs during the first trimester of pregnancy for the prevention of low birthweight. J Fam Pract 1994;39:353-7.

17 Marks JS, Koplan JP, Hogue CJ, et al. A cost-benefit/cost-effectiveness analysis of smoking cessation for pregnant women. Am J Prev Med 1990;6:282-9.

18 Ershoff DH, Quinn VP, Mullen PD, et al. Pregnancy and medical cost outcomes of a self-help prenatal smoking cessation program in a HMO. Public Health Rep 1990; 105:340-7.

19 Floyd RL, Rimer BK, Giovino GA, et al. A review of smoking in pregnancy: effects on pregnancy outcomes and cessation efforts. Annu Rev Public Health 1993;14:379-411.

20 Lam TH, He Y, Shi QL, et al. Smoking, quitting, and mortality in a Chinese cohort of retired men. Ann Epidemiol 2002;12:316-20.

21 Wen CP, Tsai SP, Chen CJ, et al. The mortality risks of smokers in Taiwan part I: cause-specific mortality. Prev Med 2004;39:528-35.

22 SAS Institute Inc. SAS/STAT user's guide, version 8. Cary, North Carolina: SAS Institute Inc, 1999.

23 Doll R, Peto R, Boreham J, et al. Mortality in relation to smoking: 50 years' observations on male British doctors. BMJ 2004;328:1519-28.

24 Godifredsen NS, Holst C, Prescott E, et al. Smoking reduction, smoking cessation, and mortality: a 16-year follow-up of 19,732 men and women from the Copenhagen Centre for Prospective Population Studies. Am J Epidemiol 2002;156:994-1001.

25 Wen CP, Tsai SP, Chen CJ, et al. Smoking attributable mortality for Taiwan and its projection to 2020 under different smoking scenarios. Tobacco Control 2005; 14(suppl I):i76-80.

26 Wen CP, Tsai SP, Cheng TY, et al. Uncovering the relation between betel quid chewing and cigarette smoking in Taiwan. Tobacco Control 2005;14(suppl I):i16-22.

27 American Cancer Society. Tobacco control country profiles. Atlanta, Georgia: American Cancer Society, 2000-03.

28 Wen CP. The Taiwan tobacco atlas. Taipei, Taiwan: United Medial Foundation and National Health Research Institutes; 2004, ISBN 957-29975-0-5.

29 American Academy of Family Physicians. Tar wars, AAFP 2004. hitp:// www.tarwars.org/index.xml (Accessed Nov 20, 2004).

30 American Society of Clinical Oncology. 2002. http://www.asco.org/ac/ 1,1003,_12-002138,00.asp (Accessed Nov 10, 2004).

31 US Department of Health and Human Services. Reducing tobacco use: a report of the Surgeon General. Atlanta, Georgia: US Department of Health and Human Services, Centers for Disease Control and Prevention, National Center for Chronic Disease Prevention and Health Promotion, Office on Smoking and Health, 2000.

32 Novartis Taiwan. Personal Communication. 2003. 
33 Wung SH. Analysis of inpatient care resource utilization by low birth weight premature infants. Master Thesis. (in Chinese): National Taipei Nursing College, Taipei, Taiwan, 2001.

34 Environmental Protection Agency. Respiratory health effects of passive smoking: lung cancer and other disorders. Washington DC: EPA Office of Research and Development, 1992.

35 Philip Morris International. Secondhand smoke. 2004. http:// www.philipmorrisinternational.com/pages/eng/smoking/

Secondhand_smoke.asp (Accessed Nov 10, 2004)

36 Chen LK, Shih SF, Chang HC. The arrival of a new life and smoking cessation: how fathers and mothers stop smoking for their babies. Annual Meeting of Taiwan Population Association, 2004.

37 Lin YH, Liu IW, Lin HS. 8th national survey on family and fertility in Taiwan. Taichung, Taiwan: Bureau of Health Promotion, 1998.
38 DiClemente CC, Dolan-Mullen P, Windsor RA. The process of pregnancy smoking cessation: implications for interventions. Tobacco Control 2000;9(suppl III):iii 16-21.

39 Melvin CL, Dolan-Mullen P, Windsor RA, et al. Recommended cessation counseling for pregnant women who smoke: a review of the evidence. Tobacco Control 2000;9(suppl III):iii80-4.

40 Peacock JL, Cook DG, Carey IM, et al. Maternal cotinine level during pregnancy and birthweight for gestation age. Int J Epidemiol 1998;27:647-56.

41 Eskenazi B, Prehn AW, Christianson RE. Passive and active maternal smoking as measured by serum cotinine: the effect on birthweight. Am J Public Health 1995;85:395-8.

42 Windham GC, Eaton A, Hopkins B. Evidence for an association between environmental tobacco smoke exposure and birthweight: a meta-analysis and new data. Paediatr Perinat Epidemiol 1999;13:35-57.

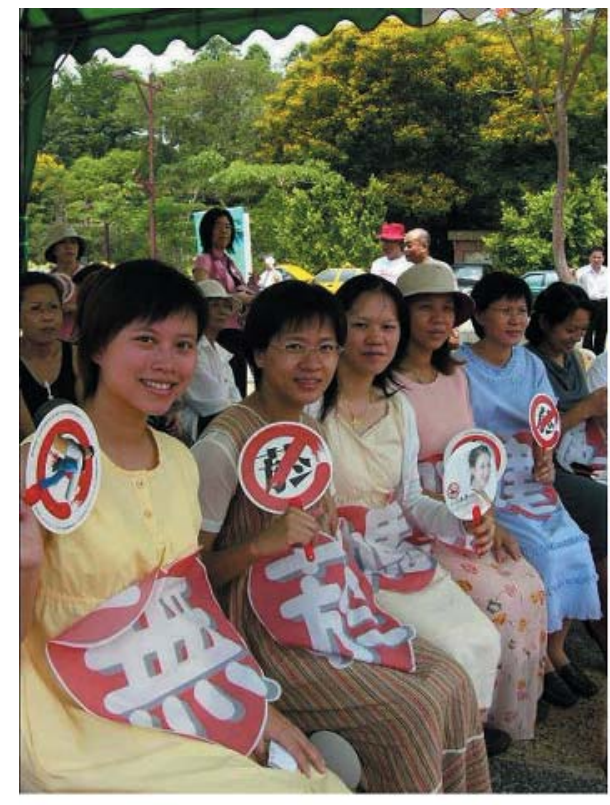

Pregnant women for smoke-free-home campaign

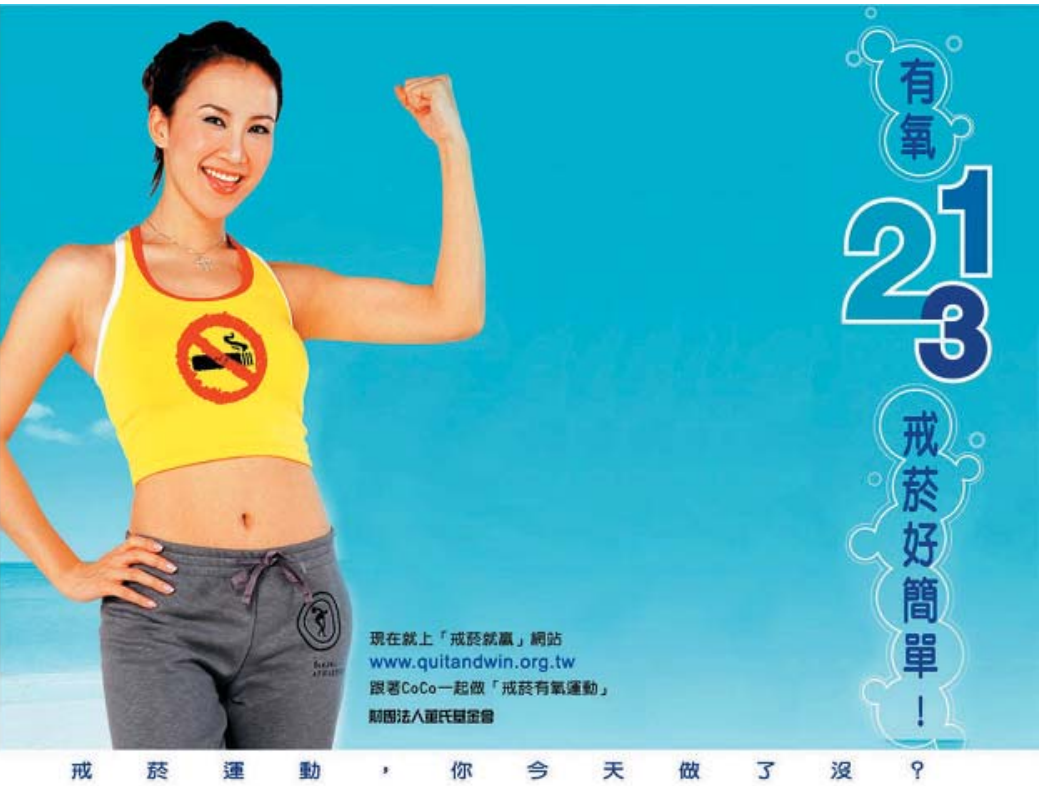

"Cessation can be facilitated by aerobics", as promoted by singer CoCo lee (John Tung Foundation) 